\title{
Association Between Air Pollutants and Hospitalization with Chronic Obstructive Pulmonary Disease in Ganzhou, China
}

\section{Xingye Zhou}

Gannan Medical University https://orcid.org/0000-0001-9218-2945

Chenwei Li

Gannan Medical College: Gannan Medical University

\section{Yanfang Gao}

Gannan Medical College: Gannan Medical University

Chuanfei Zhou

Gannan Medical College: Gannan Medical University

Xiaokang Zhang ( $\sim$ Zhangxiaokaju@163.com )

Gannan Medical College: Gannan Medical University

\section{Research}

Keywords: Air Pollution, Particulate matter, Lung Diseases, Chronic Obstructive Pulmonary Diseases, Generalized additive models, Hospital admissions

Posted Date: August 12th, 2021

DOl: https://doi.org/10.21203/rs.3.rs-789568/v1

License: (c) (1) This work is licensed under a Creative Commons Attribution 4.0 International License. Read Full License 


\section{Abstract}

Background. The evidence of the harm of air pollutants to respiratory health in inland cities in southern China is relatively limited. Therefore, it is necessary to explore the relationship between air pollutants and the number of hospitalized patients with chronic obstructive pulmonary disease (COPD) in this area.

Method. The number of inpatients with COPD, air quality data and meteorological data in the First Affiliated Hospital of Gannan Medical University in Ganzhou City from 2016 to 2020 were collected. Generalized additive models were used to analyze the lagged effects of air pollutants and their health effects on the number of hospitalizations for COPD.

Results. Among a variety of pollutants, the air pollutants $\mathrm{PM}_{2.5}, \mathrm{PM}_{10}, \mathrm{NO}_{2}$ and $\mathrm{O}_{3}$ in Ganzhou City have a significant impact on the number of hospitalized patients with COPD. Using $\mathrm{PM}_{2.5}$ as an example, the single day lag effect and cumulative lag effect reached their maximum at lag 6 day and lag 12 day, respectively, at which time the number of hospitalizations due to COPD increased by $2.82 \%$ and $6.60 \%$, respectively. After adjusting for other pollutants, it was found that the impact of $\mathrm{PM}_{2.5}$ on the number of hospitalizations of COPD patients did not change much. Compared with the cold season, the changes of $\mathrm{PM}_{2.5}, \mathrm{PM}_{10}$ and $\mathrm{O}_{3}$ in warm season have a greater impact on the number of inpatients with COPD.

Conclusions. The increased concentrations of $\mathrm{PM}_{2.5}, \mathrm{PM}_{10}, \mathrm{NO}_{2}$ and $\mathrm{O}_{3}$ in Ganzhou may increase the risk of COPD patients, which is one of the reasons for the increase in the number of COPD hospitalizations.

\section{Background}

Exposure to atmospheric particulates has been confirmed to be closely related to the incidence rate and mortality of respiratory diseases ${ }^{[1-4]}$. Many kinds of atmospheric pollutants, represented by $\mathrm{PM}_{2.5}$, have become a non negligible problem to harm human environmental health. They can carry many kinds of hazardous substances into the depth of human lungs ${ }^{[5]}$.

Chronic obstructive pulmonary disease (COPD), a progressive and incurable lung disease, was the top 4 leading cause of years of life lost (YLL) and the top 3 leading cause of disable-adjusted life years (DALYs) in China in $2017^{[6]}[$ For developing countries such as China, the major risk factor for causing COPD is exposure to atmospheric environmental pollutants this risk factor contributes to $58.1 \%$ of the COPD burden ${ }^{[7]}$. Many scholars have previously confirmed that air pollutants are closely related to the number of outpatients and inpatients of chronic obstructive pulmonary disease through large-scale cohort studies $^{[8-10]}$.

Ganzhou City, old region of revolution, is the largest and most populous city in Jiangxi Province, China. In recent years, with economic development, the increasing popularity of transport and the influx of township and town populations, the challenge of the residential environment in urban areas is increasing, there are not small differences in the components and concentrations of air pollutants in different 
regions ${ }^{[11]}$, and studies on the population health effects of air pollution in local areas are still limited. This study used daily monitoring data of air pollutants, hospitalization data of general hospitals and meteorological data in Ganzhou City from 2016 to 2020 to quantitatively evaluate the acute effects of major air pollutants in the air on the number of COPD hospitalizations using time series analysis.

\section{Methods}

Health data collection

We collected the data of patients with COPD in the First Affiliated Hospital of Gannan Medical University from January 1, 2016 to December 31, 2020. The data of hospitalized case includes medical record number, gender, date of birth, international statistical classification of diseases (ICD) code of discharge diagnosis and other information. Patients with chronic obstructive pulmonary disease whose ICD code (ICD code: J44) was the main disease diagnosed in discharge according to ICD-10 were included as the research objects in this study. The study was approved by the Ethics Committee of Gannan Medical University.

\section{Environmental Data Collection}

We collected daily concentrations of air pollutants from Ganzhou Environmental Monitoring Center from January 1, 2016 to December 31, 2020, including fine particulate matter $\left(P M_{2.5}\right)$, inhalable particles $\left(\mathrm{PM}_{10}\right)$, sulfur dioxide $\left(\mathrm{SO}_{2}\right)$, nitrogen dioxide $\left(\mathrm{NO}_{2}\right)$, ozone $\left(\mathrm{O}_{3}\right)$ and carbon monoxide $(\mathrm{CO})$. The average daily concentration of six air pollutants in five monitoring stations was calculated to represent the daily exposure concentration of Ganzhou residents ${ }^{[12]}$. In addition, we obtained daily meteorological data, including daily mean temperature and relative humidity, from Ganzhou Meteorological Bureau.

\section{Statistical analysis}

SPSS 22.0 software was used for statistical analysis. Descriptive analysis was used for the average daily concentration of the six air pollutants and the number of patients with COPD in the hospital every day, and rank correlation analysis was used for the mass concentration of a variety of common air pollutants and meteorological data. Similar to previous studies ${ }^{[13-16]}$, this study should use the generalized additive model (GAM) with Poisson distribution to analyze the relationship between the number of COPD hospitalizations and the concentration of air pollutants. In the model, natural cubic spline (NS) was used to adjust the long-term trend, seasonal trend and meteorological factors of time variable, and day of the week effect (DOW) was added into the model in the form of classified variable to control. The choice of degrees of freedom is based on the Akaike's Information Criterion (AIC). The GAM model is established as follows:

\section{$\log \left[E\left(Y_{i}\right)\right]=a+\beta X_{i}+n s($ time, $d f)+n s(T e m p, d f)+n s(R H, d f)$ + DOW}


In the formula, $\mathrm{E}(\mathrm{Yi})$ is the expected number of hospitalizations on the " $\mathrm{i}$ " day, the unit is the number of people; Alpha is the intercept; $\beta$ is the regression coefficient; $X i$ is the concentration of pollutants on the " $\mathrm{I} \mathrm{"}$ day, in $\mu \mathrm{g} / \mathrm{m}^{3}$ (CO in $\mathrm{mg} / \mathrm{m}^{3}$ ); $\mathrm{ns}$ is natural cubic spline function; time is a time variable, the unit is days; Temp is air temperature in degrees Celsius; $\mathrm{RH}$ is relative humidity in percentage; $\mathrm{df}$ is the degree of freedom corresponding to each variable; DOW is the weekday variable.

Air pollutants have a lag effect on population health combined with the length of lag time for the health effects of pollutants in previous studies ${ }^{[2][17]}$, this study analyzes single day lag effects $\left(\operatorname{lag}_{0}-\operatorname{lag}_{15}\right)$ and multiday lag effects $\left(\operatorname{lag}_{00}-\operatorname{lag}_{015}\right)$ over a 15 day period. The results of this paper are expressed by the excess risk (ER) and 95\% confidence interval $(\mathrm{Cl})$ of the increase of hospitalization volume. The maximum effect value within 15 days of single day lag is taken as the exposure risk estimation value of the impact of the pollutant on the inpatient, When the one-day lag effect is the largest, other single pollutants are introduced into the model in turn to establish a two pollutant model to evaluate the health effects caused by the individual and combination of multiple pollutants.

\section{Results}

Table 1 shows descriptive statistics on the number of people with COPD, air pollutants and meteorological conditions. During our five-year study, 4980 patients with COPD were hospitalized, with an average of 2.73 patients per day. The male patients accounted for a large proportion (81.61\%), most of them $(70.4 \%$ ) of the inpatients were elderly (over 65 years old). During the study period, the daily average concentrations of $\mathrm{PM}_{2.5}, \mathrm{PM}_{10}, \mathrm{SO}_{2}, \mathrm{NO}_{2}, \mathrm{O}_{3}$ and $\mathrm{CO}$ in Ganzhou City were $37.47 \mu \mathrm{g} / \mathrm{m}^{3}$ (ranging from 16.27 to $58.76 \mu \mathrm{g} / \mathrm{m}^{3}$ ), $60.06 \mu \mathrm{g} / \mathrm{m}^{3}$ (ranging from 26.24 to $83.88 \mu \mathrm{g} / \mathrm{m}^{3}$ ), $18.74 \mu \mathrm{g} / \mathrm{m}^{3}$ (ranging from 7.48 to $30.00 \mu \mathrm{g} / \mathrm{m}^{3}$ ), $23.51 \mu \mathrm{g} / \mathrm{m}^{3}$ (ranging from 9.91 to $37.11 \mu \mathrm{g} / \mathrm{m}^{3}$ ), $70.00 \mu \mathrm{g} / \mathrm{m}^{3}$ (ranging from 37.38 to $102.62 \mu \mathrm{g} / \mathrm{m}^{3}$ ) and $1.24 \mathrm{mg} / \mathrm{m}^{3}$ (range is 0.92 to $1.56 \mathrm{mg} / \mathrm{m}^{3}$ ). The daily mean concentrations of both $\mathrm{PM}_{2.5}$ and $\mathrm{PM}_{10}$ have exceeded the Chinese ambient air quality first-order concentration standards (the $\mathrm{PM}_{2.5}$ daily mean first-order concentration limit is $35 \mu \mathrm{g} / \mathrm{m}^{3} ; \mathrm{PM}_{10}$ average daily concentration limit is $50 \mu \mathrm{g} / \mathrm{m}^{3}$ ). The daily average temperature was $19.72^{\circ} \mathrm{C}$ (ranging from 11.65 to $27.79^{\circ} \mathrm{C}$ ), and the relative humidity was $74.35 \%$ (ranging from 62.17 to $86.53 \%$ ). 
Table 1

Summary statistics for air pollutants concentrations and meteorological variables

\begin{tabular}{|c|c|c|c|c|c|c|}
\hline & Mean \pm SD & Minimum & $P(25)$ & Median & $\mathrm{P}(75)$ & Maximum \\
\hline COPD & $2.73 \pm 2.04$ & 0 & 1 & 2 & 4 & 13 \\
\hline $\mathrm{PM}_{2.5}\left(\mu \mathrm{g} / \mathrm{m}^{3}\right)$ & $37.47 \pm 21.20$ & 6 & 23 & 33 & 47 & 197 \\
\hline $\mathrm{PM}_{10}\left(\mu \mathrm{g} / \mathrm{m}^{3}\right)$ & $60.06 \pm 33.82$ & 11 & 36 & 52 & 76 & 258 \\
\hline $\mathrm{SO}_{2}\left(\mu \mathrm{g} / \mathrm{m}^{3}\right)$ & $18.74 \pm 11.26$ & 2 & 11 & 16 & 23 & 73 \\
\hline $\mathrm{NO}_{2}\left(\mu \mathrm{g} / \mathrm{m}^{3}\right)$ & $23.51 \pm 13.60$ & 4 & 14 & 20 & 28 & 94 \\
\hline $\mathrm{O}_{3}\left(\mu \mathrm{g} / \mathrm{m}^{3}\right)$ & $70.00 \pm 32.62$ & 4 & 46 & 67 & 91 & 194 \\
\hline $\mathrm{cO}\left(\mathrm{mg} / \mathrm{m}^{3}\right)$ & $1.24 \pm 0.32$ & 0.60 & 1.00 & 1.20 & 1.44 & 2.90 \\
\hline Temperature $\left({ }^{\circ} \mathrm{C}\right)$ & $19.72 \pm 8.07$ & 0 & 13 & 21 & 27 & 32 \\
\hline Relative humidity(\%) & $74.35 \pm 12.18$ & 35 & 65 & 74 & 84 & 99 \\
\hline
\end{tabular}

Table 2 presents the Spearman correlation coefficients for air pollutant concentrations and meteorological variables. All the correlation coefficients between air pollutants and meteorological factors in this study were statistically significant $(P<0.05)$. Using particulate matter as an example, $\mathrm{PM}_{2.5}$ was highly positively correlated with $\mathrm{PM}_{10}(r=0.960)$, moderately correlated with $\mathrm{SO}_{2}(r=0.687)$ and $\mathrm{NO}_{2}$ $(r=0.618)$, weakly correlated with $\mathrm{O}_{3}(r=0.259)$ and $\mathrm{CO}(r=0.445)$, and negatively correlated with air temperature $(r=-0.211)$ and relative humidity $(r=-0.228) . \mathrm{PM}_{10}$ showed moderate positive correlations with $\mathrm{SO}_{2}(r=0.706), \mathrm{NO}_{2}(r=0.656)$, weak correlations with $\mathrm{O}_{3}(r=0.330)$ and $\mathrm{CO}(r=0.387)$, and negative correlations with temperature $(r=-0.127)$ and relative humidity $(r=-0.359)$. 
Table 2

Correlation analysis of air pollutants and meteorological factors

\begin{tabular}{|c|c|c|c|c|c|c|c|c|}
\hline & $\mathrm{PM}_{2.5}$ & $\mathrm{PM}_{10}$ & $\mathrm{SO}_{2}$ & $\mathrm{NO}_{2}$ & $\mathrm{O}_{3}$ & $\mathrm{CO}$ & Temperature & $\begin{array}{l}\text { Relative } \\
\text { humidity }\end{array}$ \\
\hline $\mathrm{PM}_{2.5}$ & 1 & & & & & & & \\
\hline $\mathrm{PM}_{10}$ & 0.960 & 1 & & & & & & \\
\hline $\mathrm{SO}_{2}$ & 0.687 & 0.706 & 1 & & & & & \\
\hline $\mathrm{NO}_{2}$ & 0.618 & 0.656 & 0.510 & 1 & & & & \\
\hline $\mathrm{O}_{3}$ & 0.259 & 0.330 & 0.221 & -0.093 & 1 & & & \\
\hline $\mathrm{CO}$ & 0.445 & 0.387 & 0.292 & 0.401 & -0.182 & 1 & & \\
\hline Temperature & -0.211 & -0.127 & 0.066 & -0.394 & 0.369 & -0.321 & 1 & \\
\hline $\begin{array}{l}\text { Relative } \\
\text { humidity }\end{array}$ & -0.228 & -0.359 & -0.294 & -0.075 & -0.645 & 0.210 & -0.315 & 1 \\
\hline $\begin{array}{l}\text { Notes: all cor } \\
\mathrm{PM}_{10} \text { : inhala }\end{array}$ & $\begin{array}{l}\text { n coeff } \\
\text { ticles; }\end{array}$ & $\begin{array}{l}\text { ents a } \\
\text { 2: sulf }\end{array}$ & $\begin{array}{l}\text { tatistica } \\
\text { lioxide; }\end{array}$ & $\begin{array}{l}\text { y signifi } \\
\mathrm{O}_{2}: \text { nitro }\end{array}$ & $\begin{array}{l}\text { nt }(p<0 \\
\text { n diox }\end{array}$ & $\begin{array}{l}\text { ). } \mathrm{PM}_{2} \\
; \mathrm{O}_{3}: \mathrm{O}\end{array}$ & fine particulate & matter; \\
\hline
\end{tabular}

The single day lag effect analysis by single pollution generalized additive model showed (Fig. 1) that the effects of $\mathrm{PM}_{2.5}$ and $\mathrm{PM}_{10}$ on the number of COPD hospitalization reached the maximum at lag 6 day, with $\mathrm{ER}$ and $95 \% \mathrm{Cl}$ of $2.82(1.00,4.67)$ and $1.31(0.26,2.36)$, respectively. The effect of $\mathrm{NO}_{2}$ on the hospital volume of COPD reached its maximum at lag 9 day, with an ER and $95 \% \mathrm{Cl}$ of $3.56(1.17,6.19)$, respectively. The effect of $\mathrm{O}_{3}$ on the hospital volume of COPD reached its maximum at lag 1 day, with an ER and $95 \% \mathrm{Cl}$ of $1.45(0.17,2.74)$, respectively.

The single pollution cumulative lag effect analysis showed (Fig. 2), the cumulative effect of $\mathrm{PM}_{2.5}$ and $\mathrm{PM}_{10}$ on the hospital volume of COPD began to appear continuously at lag 6 day (the cumulative lag effect of $\mathrm{PM}_{10}$ appeared briefly at lag 2 day), and presented a short-term progressive increase trend and reached the cumulative effect maximum at lag 12 day and 10 day, respectively, Their maximum excess risk and $95 \% \mathrm{Cl}$ were $6.60(2.34,11.04)$ and $3.51(1.28,5.79)$, respectively. The cumulative effect of $\mathrm{SO}_{2}$ on the number of hospitalizations for slow conducting lung disease appeared at a lag of 10 days, and it had an excess risk and $95 \% \mathrm{Cl}$ of $8.34(0.08,17.28)$. The cumulative effect of $\mathrm{NO}_{2}$ on the number of COPD hospitalizations reached its maximum at lag 11 day, and its excess risk and $95 \% \mathrm{Cl}$ were 7.06 $(0.45,14.10)$, respectively. The cumulative effect of $\mathrm{O}_{3}$ on COPD hospital volume both appeared at lag 2 day and reached its maximum at lag 13 day, when it reached its maximum value, its excess risk and $95 \%$ Cl was $2.94(0.57,5.36)$. 
The two pollution model showed(Fig. 3) that the effects of $\mathrm{PM}_{2.5}$ on the hospital volume of COPD were found to be slightly higher after adjusting for $\mathrm{SO}_{2}, \mathrm{NO}_{2}, \mathrm{O}_{3}$, and $\mathrm{CO}$, respectively, than the results of the single pollution model, which found no statistical significance after adjusting for $\mathrm{PM}_{10}$; after adjusting for $\mathrm{NO}_{2}, \mathrm{O}_{2}$ as well as $\mathrm{CO}$, it was found that $\mathrm{PM}_{10}$ had a slightly higher effect on the hospital volume of COPD than its single pollution model effect level; compared with the single pollutant models, the effects of $\mathrm{SO}_{2}$ on slow resistance lung hospitalization were statistically significant after adjusting for $\mathrm{NO}_{2}, \mathrm{O}_{3}$, as well as $\mathrm{CO}$; after adjusting for other pollutants separately, $\mathrm{NO}_{2}$ was found to have a higher impact on the number of chronic obstructive pulmonary hospitalizations than the results from the single pollutant model; found that the effect of $\mathrm{O}_{3}$ on the hospital volume of COPD remained statistically significant after adjusting for $\mathrm{NO}_{2}, \mathrm{O}_{3}$ as well as $\mathrm{CO}$; the two pollution model of $\mathrm{CO}$ showed that after adjusting for other pollutants, the effect of $\mathrm{CO}$ on the hospital volume of COPD was similar to the estimation results of its single pollution model, and no more statistically significant values were found.

We subsequently performed subgroup analyses(Fig. 4). We found that among the effects of pollutants in different seasons, the cumulative lag effect of the concentration changes of $\mathrm{PM}_{2.5}, \mathrm{PM}_{10}$ and $\mathrm{O}_{3}$ in warm season was statistically significant. Compared with the cold season, every $10 \mu \mathrm{g} / \mathrm{m}^{3}$ change of $\mathrm{PM}_{2.5}$ in the warm season will lead to an increase of $13.95 \%(5.74 \%$ 22.81\%) in the hospitalization of COPD after a cumulative lag of 7 days; For every $10 \mu \mathrm{g} / \mathrm{m}^{3}$ change of $\mathrm{PM}_{10}$ in warm season, the hospitalization of COPD will increase by $8.45 \%(3.77 \% \sim 13.34 \%)$ after 7 days of cumulative lag; For every $1 \mathrm{mg} / \mathrm{m}^{3}$ change of $\mathrm{O}_{3}$ in warm season, the hospitalization of COPD will increase by $1.48 \%(4.10 \% \sim 6.79 \%)$ after 5 days of cumulative lag. In general, compared with the cold season, the changes of $\mathrm{PM}_{2.5}, \mathrm{PM}_{10}$ and $\mathrm{O}_{3}$ concentrations in the warm season have a greater impact on COPD hospitalization.

\section{Discussion}

In this study, we investigated the short-term effects of multiple common air pollutants on the number of hospitalizations for COPD among residents of Ganzhou City, Jiangxi Province, China, from January 1 , 2016 to October 31, 2020. Our results showed a strong positive association between short-term air pollutant exposure and hospital admissions for COPD.

Many previous studies have pointed out the inevitable link between short-term acute exposure to $\mathrm{PM}_{2.5}$ and the number of hospitalizations for chronic obstructive pulmonary disease ${ }^{[18-21]}$. In a single pollutant single day lag model, our study found that each $10 \mu \mathrm{g} / \mathrm{m}^{3}$ increase in $\mathrm{PM}_{2.5}$ concentration (lag 6 day) was associated with a $2.82 \%$ increase in hospitalization for chronic obstructive pulmonary disease, which is consistent with previous findings. A time-series analysis ${ }^{[22]}$ in Beijing estimated that a $0.67 \%$ increase in daily hospital admissions for COPD patients was associated with each $10 \mu \mathrm{g} / \mathrm{m}^{3}$ increase in inhalable $\mathrm{PM}_{2.5}$. Studies by Zhang et al ${ }^{[23]}$ and Heinrich et al ${ }^{[24]}$ found that each $10 \mu \mathrm{g} / \mathrm{m}^{3}$ increase in $\mathrm{PM}_{2.5}$ can cause a $2.17 \%$ and $2.5 \%$ increase in COPD hospitalizations, respectively. Li et al ${ }^{[25]}$ estimated that the 
incremental change in COPD hospitalization associated with a $10 \mu \mathrm{g} / \mathrm{m}^{3}$ increase in $\mathrm{PM}_{2.5}$ (lag 0-7 days) was $3.1 \%$ (95\% confidence interval: $1.6 \%-4.6 \%)$.

Effect estimates based solely on single day pollutant exposure are likely to underestimate the true health effects of air pollutants on hospital admissions for respiratory diseases ${ }^{[26]}$. Therefore in single pollutant models, we pay more attention to the results of cumulative lag effects. Our study observed that the largest effect of $\mathrm{PM}_{2.5}$ on COPD patient visits occurred in the distribution lag period of $0-7$ days, within a lag week. This finding is slightly different from the results of previous studies. Hwang et al ${ }^{[18]}$ studied a single pollutant model within five days of lag and found that the effect of $\mathrm{PM}_{2.5}$ on hospital volume for COPD reached its maximum at cumulative lag 0-5 days. A time-series study of all large hospitals in Beijing analyzed the effect of atmospheric $\mathrm{PM}_{2.5}$ on the number of COPD hospitalizations and found that the cumulative lag effect of $\mathrm{PM}_{2.5}$ on COPD hospital volume increased day by day starting at cumulative lag $0-1$ days, reached a maximum at cumulative lag $0-6$ days, and decreased thereafter (cumulative lag $0-6$ days) ${ }^{[27]}$. We continued to extend the observation period relative to prior studies and found that the health effects of cumulative $\mathrm{PM}_{2.5}$ exposure on COPD increased cyclically with longer distribution lags, reaching effect maxima at distribution lags of $0-12$ days.

The question of whether adjusted two pollutant models better describe the association of pollutants with the number of hospitalizations for COPD than single pollutants has been debated. A single day lag effect maximum (lag 6 day) for $\mathrm{PM}_{2.5}$ was selected in the $\mathrm{PM}_{2.5}$ two pollutant model of this study. The results showed that the association of $\mathrm{PM}_{2.5}$ with the number of chronic obstructive pulmonary disease hospitalizations was elevated after adjustment for $\mathrm{NO}_{2}$ compared with single pollutant models; The association of $\mathrm{PM}_{2.5}$ with the number of hospitalizations for chronic obstructive pulmonary disease changed little after adjustment for $\mathrm{SO}_{2}, \mathrm{O}_{3}$, and $\mathrm{CO} ; \mathrm{PM}_{2.5}$ did not present statistical association with the number of chronic obstructive pulmonary disease hospitalizations after adjustment for $\mathrm{PM}_{10}$. Some studies have found that after $\mathrm{SO}_{2}, \mathrm{NO}_{2}$ and $\mathrm{CO}$ adjustment, the relationship between $\mathrm{PM}_{2.5}$ and $\mathrm{COPD}$ outpatient and inpatient quantity is weakened or not significant ${ }^{[28-29]}$. A study in southwestern Taiwan suggested that $\mathrm{PM}_{2.5}$ exposure was more significantly correlated with hospital stay in patients with COPD exacerbation after adjusting for $\mathrm{O}_{3}$ and $\mathrm{NO}_{2}{ }^{[20]}$.

When we compare the risk estimates of warm season and cold season, we find that the impact of warm season is greater. Our results are similar to those of most previous studies ${ }^{[22][30]}$. According to our analysis, in recent years, the public has enhanced their awareness of protection. When encountering severe fog and haze, they reduce going out and outdoor sports. Even if they have to go out, they will wear masks. Even indoors, they will use air purification devices to improve the indoor air quality. Air pollution is more serious in the cold season. On the contrary, in the warm season, most people spend more time outdoors, and the windows are often kept open and ventilated. Therefore, ordinary residents are more likely to be directly exposed to air pollution in warm and humid seasons. There was a disagreement in the study by Nascimento et a ${ }^{[31]}$, who found that those born during winter tended to have higher years of life 
lost due to respiratory diseases compared to those born during other seasons. It is worth mentioning that the pollution situation was obviously worse in winter. Therefore winter tends to be a season with a high incidence of respiratory diseases. But the analysis of our study is that, assuming the same situation of air pollution during the cold season as during the warm season, the effect of the modification of the air pollutant concentration during the warm season on COPD hospitalization is more significant.

There are still some problems in our research. First of all, the air pollutant exposure data we collected are all obtained from five fixed air monitoring points in the urban area, and only a few fixed points of environmental exposure dose are measured. It is difficult to quantify the specific biological effective dose of human exposure. This error may lead our research to misjudge the impact of air pollutants. Secondly, our data source is only from a general hospital in Ganzhou City, in which the daily number of COPD patients is relatively small, which is not suitable for multi classification subgroup analysis, which may lead us to ignore some important links between air pollutants and COPD. This may lead us to ignore some important links between air pollutants and COPD. In the future, large-scale clinical multicenter studies will be needed to verify these results. Thirdly, we only balanced other pollutants, time trend, temperature, relative humidity and weekend effect in the model, while other influencing factors such as legal holidays, pandemic influenza and other variables have not been included in the model, which can not truly reflect the relationship between air pollutants and the number of inpatients with COPD.

\section{Conclusions}

In conclusion, this study further demonstrates that short-term acute exposure to air pollutants may increase the hospitalization risk of COPD in Ganzhou City, Jiangxi Province, China. On the basis of previous studies, we further provide data support on the lag effect of single or multiple pollutants. This study confirmed that reducing the concentration of air pollutants is an effective preventive measure to reduce the incidence of COPD, the number of inpatients and the corresponding medical economic burden.

\section{Abbreviations}

COPD: Chronic Obstructive Pulmonary Disease; GAM: Generalized Additive Model; NS: natural cubic spline ; AIC: the Akaike's Information Criterion ; df: degree of freedom ; ER: excess risk; ICD: international statistical classification of diseases; $\mathrm{PM}_{2.5}$ : fine particulate matter $; \mathrm{PM}_{10}$ : inhalable particles; $\mathrm{SO}_{2}$ : sulfur dioxide; $\mathrm{NO}_{2}$ : nitrogen dioxide; $\mathrm{O}_{3}$ : ozone; $\mathrm{CO}$ : carbon monoxide; $\mathrm{YLL}$ : years of life lost; DALYs: disableadjusted life years; DOW: day of the week effect; Cl: confidence interval

\section{Declarations}

Ethics approval and consent to participate

The study was approved by the Ethics Committee of Gannan Medical University

Consent for publication 
Not applicable

Availability of data and materials

The data sources used in this study are included in this paper

Competing interests

No competing interests

Funding

This study was supported by the doctoral startup project of Gannan Medical College (QD201901) and the science and technology research project of Jiangxi Provincial Department of Education (GJJ190786)

Authors' contributions

$\mathrm{XZ}$ carries out literature retrieval, and determines the research direction and data analysis according to the existing literature. CL participated in the data collection of the article and assisted in the statistical analysis. CZ and YG explained the data results, discussed them in combination with the existing articles, and wrote the first draft of the article. XZ is the principal and corresponding author of the subject. It is mainly responsible for contacting the hospital to provide the data required for this study, and putting forward modification opinions on the first draft of the article. Finally, all authors read and approved the final manuscript

Acknowledgements

Not applicable

\section{References}

[1] Ferreira TM, Forti MC, de Freitas CU, Nascimento FP, Junger WL, Gouveia N. Effects of Particulate Matter and Its Chemical Constituents on Elderly Hospital Admissions Due to Circulatory and Respiratory Diseases. Int J Environ Res Public Health. 2016;13(10):947.

[2] Li H, Li X, Zheng H, et al. Ultrafine particulate air pollution and pediatric emergency-department visits for main respiratory diseases in Shanghai, China. Sci Total Environ. 2021;775:145777.

[3] Sacramento DS, Martins LC, Arbex MA, Pamplona YAP. Atmospheric Pollution and Hospitalization for Cardiovascular and Respiratory Diseases in the City of Manaus from 2008 to 2012. Scientific World Journal. 2020;2020:8458359.

[4] Rodríguez-Camargo LA, Sierra-Parada RJ, Blanco-Becerra LC. Spatial analysis of PM2.5 concentrations in Bogotá according to the World Health Organization air quality guidelines for cardiopulmonary diseases, 2014-2015. Análisis espacial de las concentraciones de PM2,5 en Bogotá 
según los valores de las guías de la calidad del aire de la Organización Mundial de la Salud para enfermedades cardiopulmonares, 2014-2015. Biomedica. 2020;40(1):137-152.

[5] Anderson HR, Bremner SA, Atkinson RW, Harrison RM, Walters S. Particulate matter and daily mortality and hospital admissions in the west midlands conurbation of the United Kingdom: associations with fine and coarse particles, black smoke and sulphate. Occup Environ Med. 2001;58(8):504-510.

[6] Zhou M, Wang H, Zeng X, et al. Mortality, morbidity, and risk factors in China and its provinces, 19902017: a systematic analysis for the Global Burden of Disease Study 2017 [published correction appears in Lancet. 2020 Jul 4;396(10243):26]. Lancet. 2019;394(10204):1145-1158.

[7] GBD 2015 Chronic Respiratory Disease Collaborators. Global, regional, and national deaths, prevalence, disability-adjusted life years, and years lived with disability for chronic obstructive pulmonary disease and asthma, 1990-2015: a systematic analysis for the Global Burden of Disease Study 2015 [published correction appears in Lancet Respir Med. 2017 Oct;5(10):e30]. Lancet Respir Med. 2017;5(9):691-706.

[8] Shin S, Bai L, Burnett RT, et al. Air Pollution as a Risk Factor for Incident Chronic Obstructive Pulmonary Disease and Asthma. A 15-Year Population-based Cohort Study. Am J Respir Crit Care Med. 2021;203(9):1138-1148.

[9] Liu S, Jørgensen JT, Ljungman P, et al. Long-term exposure to low-level air pollution and incidence of chronic obstructive pulmonary disease: The ELAPSE project. Environ Int. 2021;146:106267.

[10] Han C, Oh J, Lim YH, Kim S, Hong YC. Long-term exposure to fine particulate matter and development of chronic obstructive pulmonary disease in the elderly. Environ Int. 2020;143:105895.

[11] Plummer LE, Ham W, Kleeman MJ, et al. Influence of season and location on pulmonary response to California's San Joaquin Valley airborne particulate matter [J]. J Toxicol Environ Health A. 2012;75(5):253-71.

[12] Zhao, Y., Wang, S., Lang, L., Huang, C., Ma, W., Lin, H., 2017. Ambient fine and coarse particulate matter pollution and respiratory morbidity in Dongguan, China. Environ.Pollut. 222, 126-131.

[13] Nascimento AP, Santos JM, Mill JG, et al. Association between the incidence of acute respiratory diseases in children and ambient concentrations of $\mathrm{SO}_{2}, \mathrm{PM}_{10}$ and chemical elements in fine particles. Environ Res. 2020;188:109619.

[14] Mokoena KK, Ethan CJ, Yu Y, Shale K, Liu F. Ambient air pollution and respiratory mortality in Xi'an, China: a time-series analysis. Respir Res. 2019;20(1):139.

[15] Chai G, He H, Sha Y, Zhai G, Zong S. Effect of $\mathrm{PM}_{2.5}$ on daily outpatient visits for respiratory diseases in Lanzhou, China. Sci Total Environ. 2019;649:1563-1572. 
[16] Peng L, Xiao S, Gao W, et al. Short-term associations between size-fractionated particulate air pollution and COPD mortality in Shanghai, China. Environ Pollut. 2020;257:113483.

[17] Liu Y, Chen S, Xu J, et al. The association between air pollution and outpatient and inpatient visits in Shenzhen, China [J]. International Journal of Environmental Research and Public Health, 2018, 15(2):178.

[18] Hwang SL, Lin YC, Guo SE, Chou CT, Lin CM, Chi MC. Fine particulate matter on hospital admissions for acute exacerbation of chronic obstructive pulmonary disease in southwestern Taiwan during 20062012. Int J Environ Health Res. 2017;27(2):95-105.

[19] Cheng $M-H, C h i u ~ H-F, Y$ ang $C-Y$. Coarse particulate air pollution associated with increased risk of hospital admissions for respiratory diseases in a tropical city, Kaohsiung, Taiwan. Int J Environ Res Public Health. 2015;12(10):13053-13068.

[20] Slama A, Śliwczyński A, Woźnica J, et al. Impact of air pollution on hospital admissions with a focus on respiratory diseases: a time-series multi-city analysis [published correction appears in Environ Sci Pollut Res Int. 2020 Jun;27(17):22139]. Environ Sci Pollut Res Int. 2019;26(17):16998-17009.

[21] DeVries R, Kriebel D, Sama S. Outdoor air pollution and COPD-related emergency department visits, hospital admissions, and mortality: a meta-analysis. J Chronic Obstr Pulm Dis. 2017;14(1):113-121.

[22] Tian Y, Xiang X, Juan J, et al. Short-term effects of ambient fine particulate matter pollution on hospital visits for chronic obstructive pulmonary disease in Beijing, China. Environ Health. 2018;17(1):21.

[23] Zhang S, Li G, Tian L, Guo Q, Pan X. Short-term exposure to air pollution and morbidity of COPD and asthma in East Asian area: A systematic review and meta-analysis. Environ Res. 2016;148:15-23.

[24] Heinrich J, Schikowski T. COPD patients as vulnerable subpopulation for exposure to ambient air pollution. Curr Environ Health Rep.2018;5(1):70-76.

[25] Li MH, Fan LC, Mao B, Yang JW, Choi AM, Cao WJ, Short-term Exposure XJF. To ambient fine particulate matter increases hospitalizations and mortality in COPD: a systematic review and metaanalysis. Chest. 2016;149(2):447-58.

[26] Bravo MA, Ebisu K, Dominici F, Wang Y, Peng RD, Bell ML. Airborne Fine Particles and Risk of Hospital Admissions for Understudied Populations: Effects by Urbanicity and Short-Term Cumulative Exposures in 708 U.S. Counties. Environ Health Perspect. 2017;125(4):594-601.

[27] Gao N, Li C, Ji J, et al. Short-term effects of ambient air pollution on chronic obstructive pulmonary disease admissions in Beijing, China (2013-2017). Int J Chron Obstruct Pulmon Dis. 2019;14:297-309.

[28] Zhao Y, Wang S, Lang L, Huang C, Ma W, Lin H. Ambient fine and coarse particulate matter pollution and respiratory morbidity in Dongguan, China. Environ Pollut. 2017;222:126-131. 
[29] Sun Q, Liu C, Chen R, et al. Association of fine particulate matter on acute exacerbation of chronic obstructive pulmonary disease in Yancheng, China. Sci Total Environ. 2019;650(Pt 2):1665-1670.

[30] Zhang Z, Wang J, Chen L, et al. Impact of haze and air pollution-related hazards on hospital admissions in Guangzhou, China. Environ Sci Pollut Res Int. 2014;21(6):4236-4244.

[31] Yang T, He T, Huang J, Li G. Impact of birth season on the years of life lost from respiratory diseases in the elderly related to ambient $\mathrm{PM}_{2.5}$ exposure in Ningbo, China. Environ Health Prev Med. 2021;26(1):74.

\section{Figures}


A

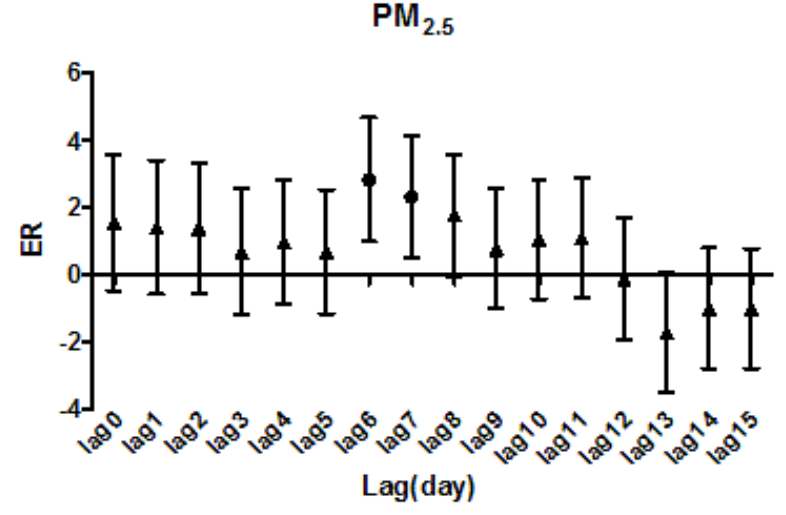

C

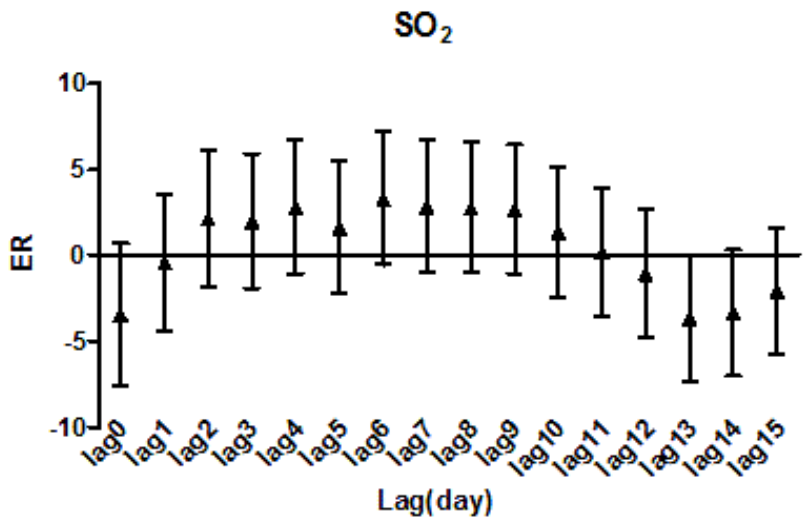

E

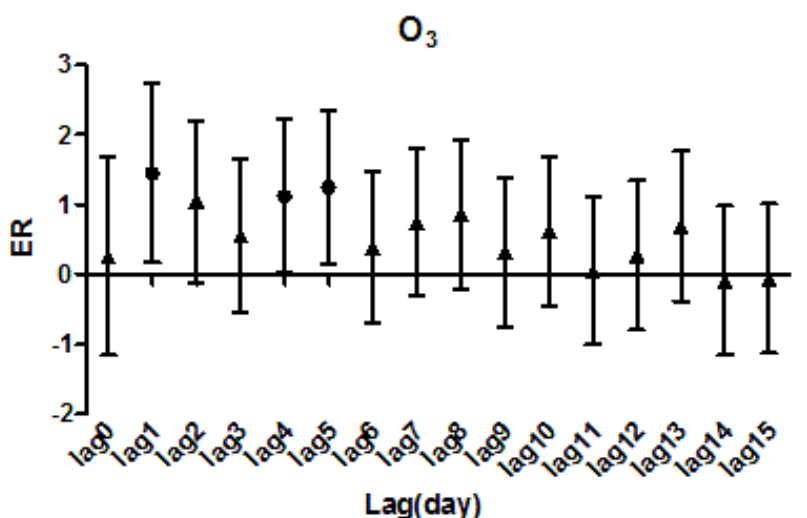

B

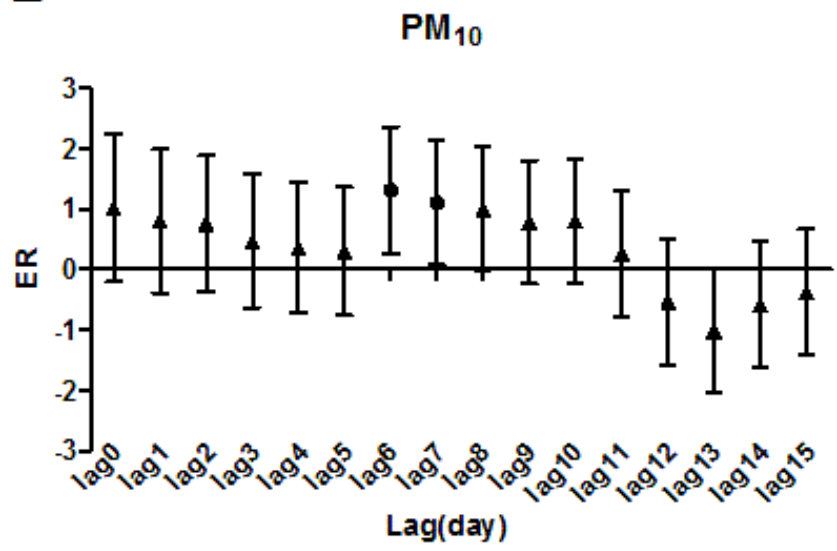

D

$\mathrm{NO}_{2}$

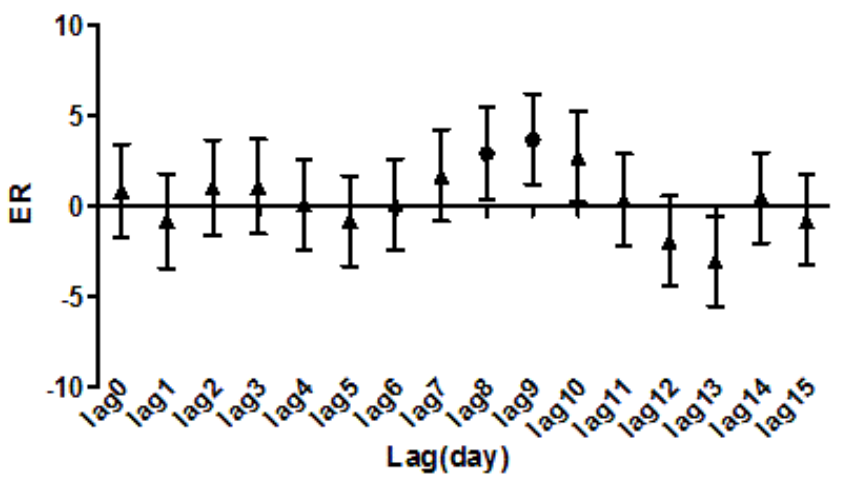

$\mathbf{F}$

co

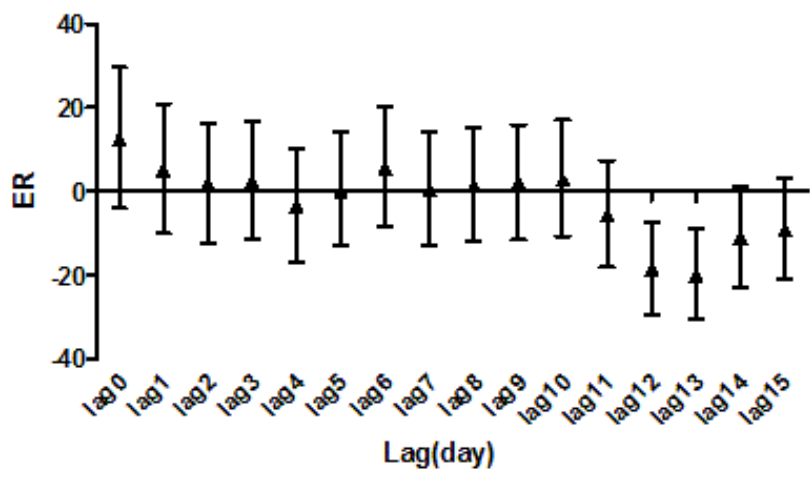

\section{Figure 1}

single-day lag model Notes: excess risk changes with 95\% Cls in COPD admission visits with per 10 $\mu \mathrm{g} / \mathrm{m} 3$ increase in PM2.5 (A), PM10 (B), SO2 (C), NO2 (D), O3 (E), and CO (F) levels by single-day lag model. For CO, excess risk change corresponded to per $10 \mathrm{mg} / \mathrm{m} 3$ increase of CO levels. ER: excess risk; Cl: confidence interval; PM2.5: fine particulate matter; PM10: inhalable particles; SO2: sulfur dioxide; NO2: nitrogen dioxide; 03: ozone; CO: carbon monoxide. 
A

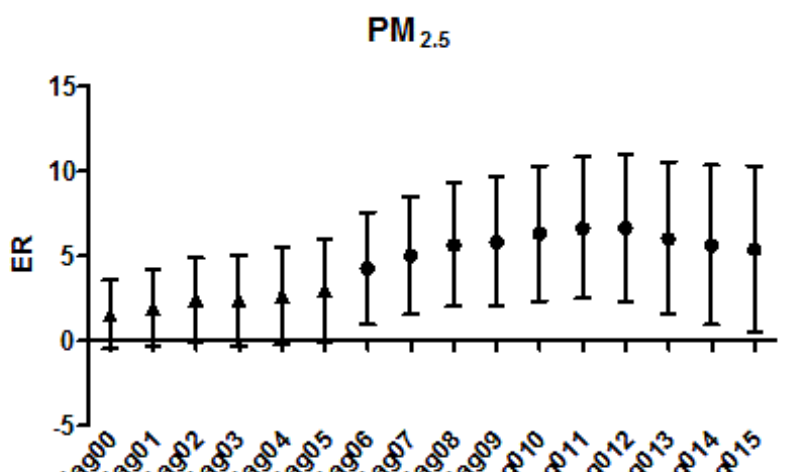

Lag(day)

C

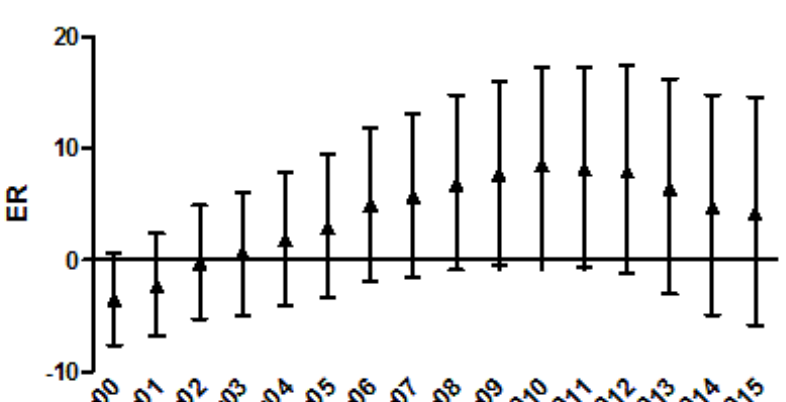

-

Lag(day)

E

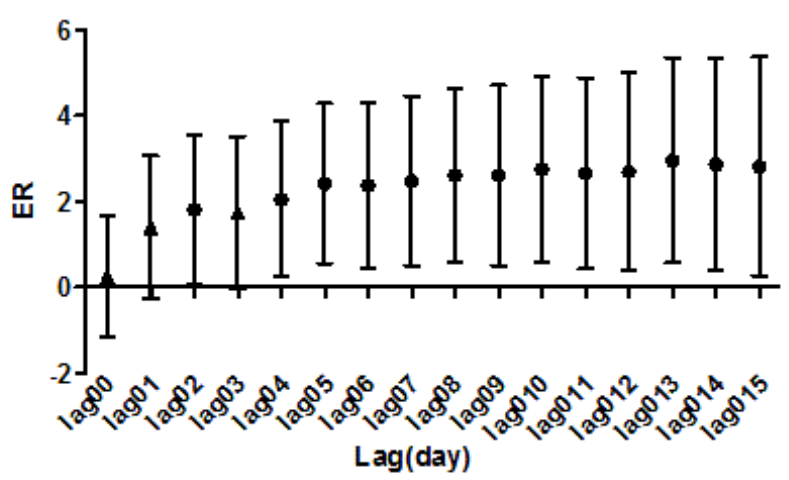

B

$\mathrm{PM}_{10}$

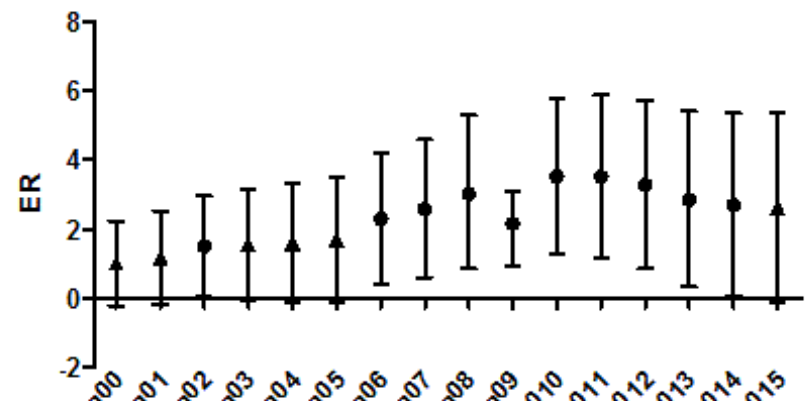

Lag(day)

D

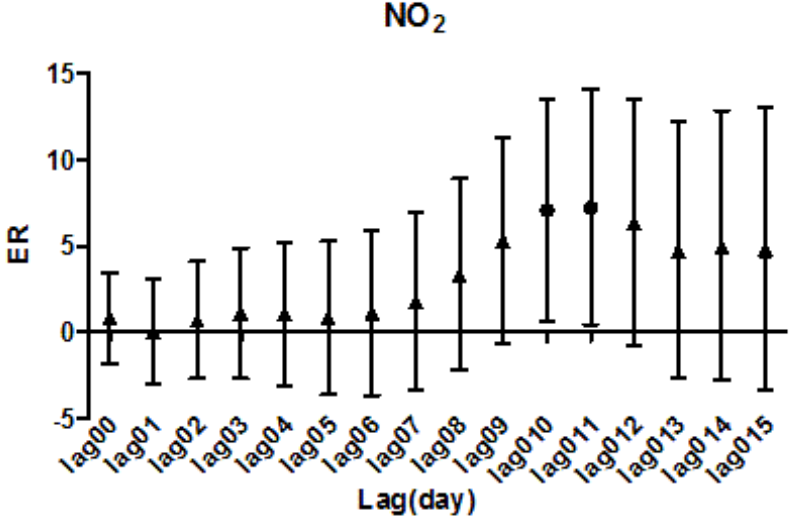

F

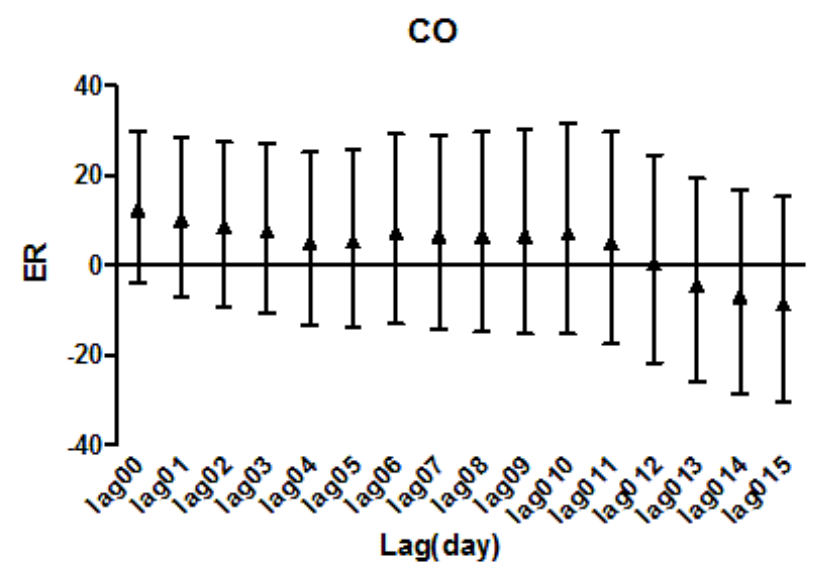

Figure 2

multiday lag model Notes: excess risk changes with 95\% Cls in COPD admission visits with per $10 \mu \mathrm{g} / \mathrm{m} 3$ increase in PM2.5 (A), PM10 (B), SO2 (C), NO2 (D), 03 (E), and CO (F) levels by multiday lag model. For $\mathrm{CO}$, excess risk change corresponded to per $1 \mathrm{mg} / \mathrm{m} 3$ increase of CO levels. ER: excess risk; $\mathrm{Cl}$ : confidence interval; PM2.5: fine particulate matter; PM10: inhalable particles; SO2: sulfur dioxide; NO2: nitrogen dioxide; 03: ozone; CO: carbon monoxide. 
A

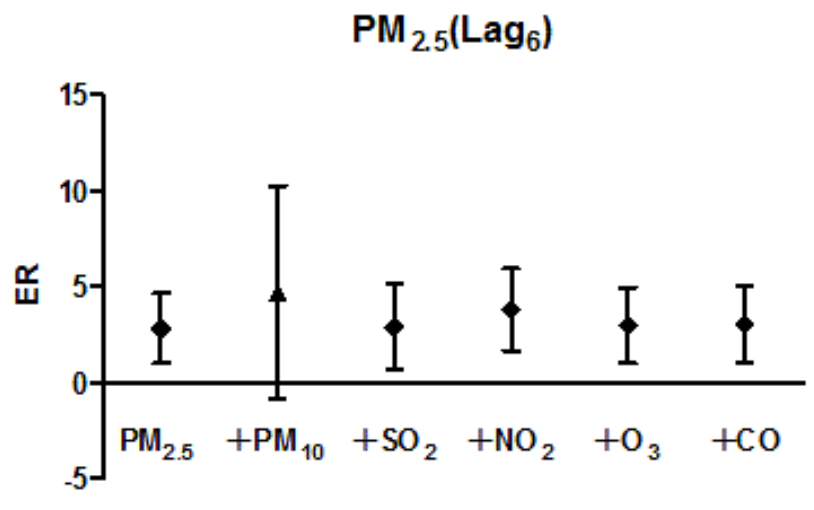

C

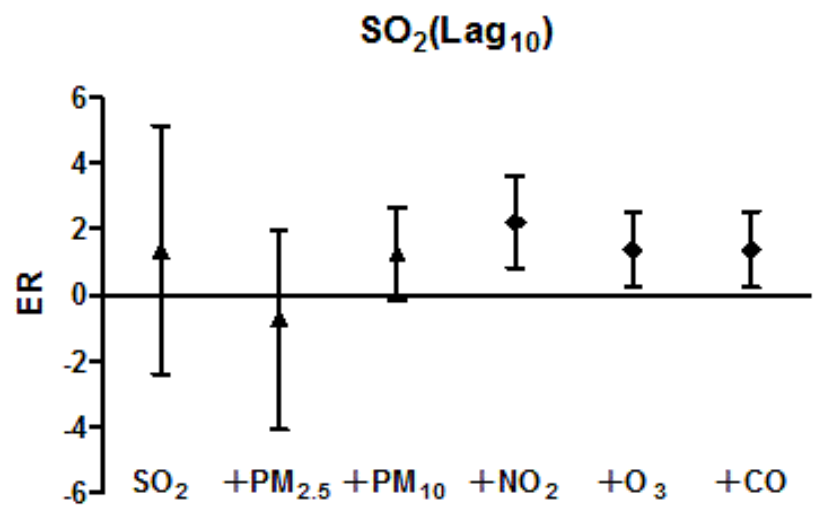

E

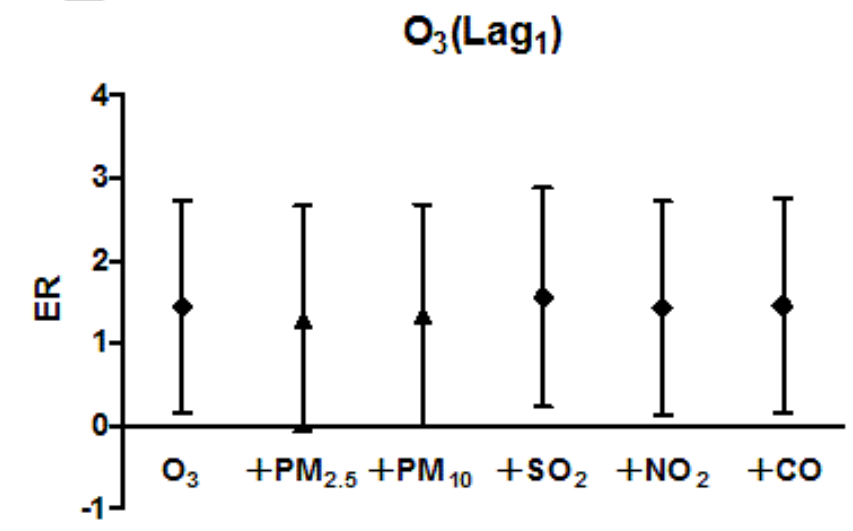

B

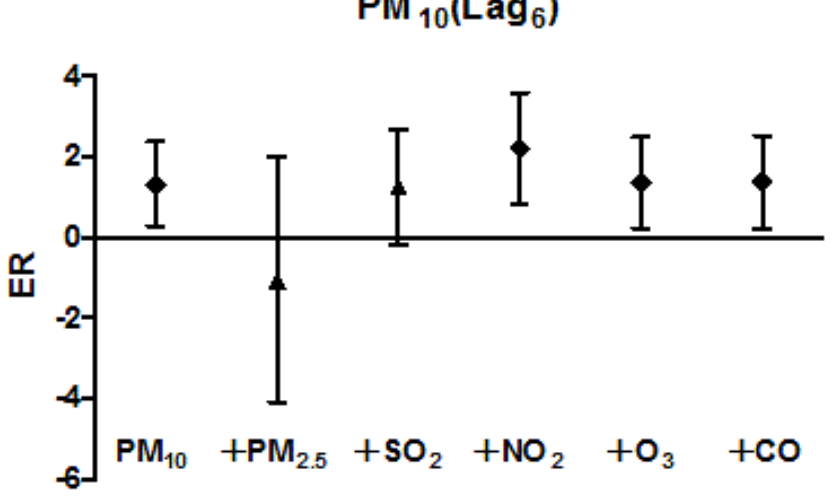

D

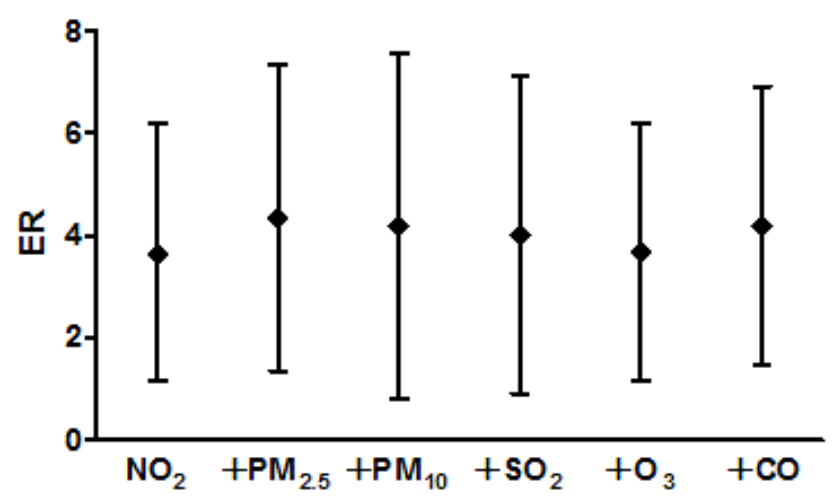

$\mathbf{F}$

$\mathrm{CO}\left(\operatorname{Lag}_{0}\right)$

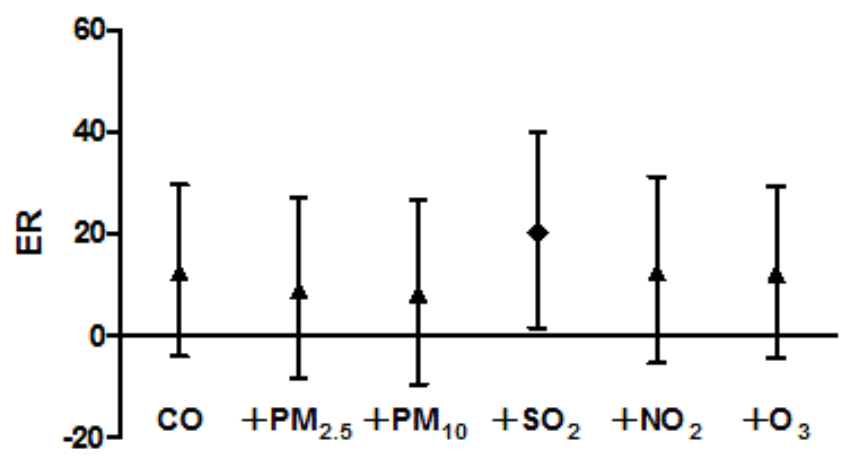

\section{Figure 3}

the two pollutant model Notes: the excess risk of COPD changes with the increase of $10 \mu \mathrm{g} / \mathrm{m} 3$ of different pollutants.(A) PM2.5(lag6), (B) PM10(lag6), (C) SO2(lag10), (D) NO2(lag9), (E) O3(lag1), (F) $\mathrm{CO}$ (lag0). For $\mathrm{CO}$, excess risk change corresponded to per $1 \mathrm{mg} / \mathrm{m} 3$ increase of CO levels. ER: excess risk; Cl: confidence interval; PM2.5: fine particulate matter; PM10: inhalable particles; SO2: sulfur dioxide; NO2: nitrogen dioxide; 03: ozone; CO: carbon monoxide. 


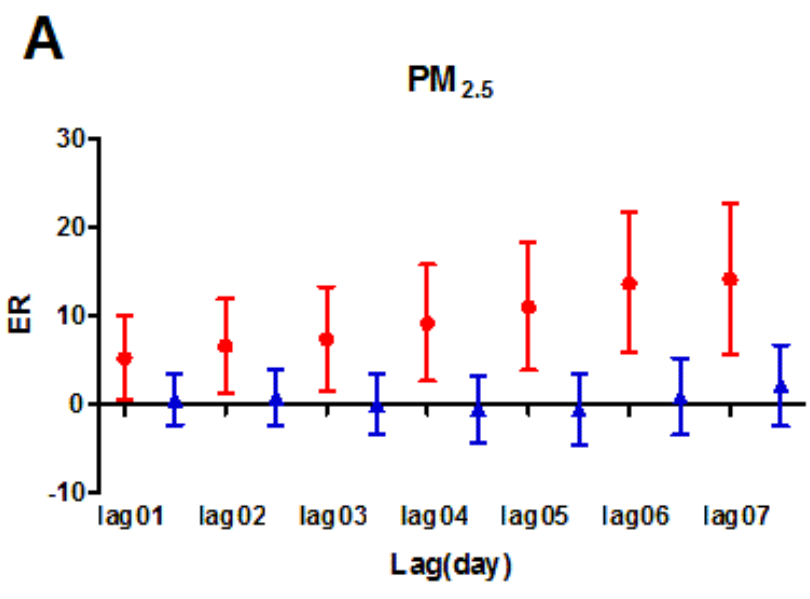

C

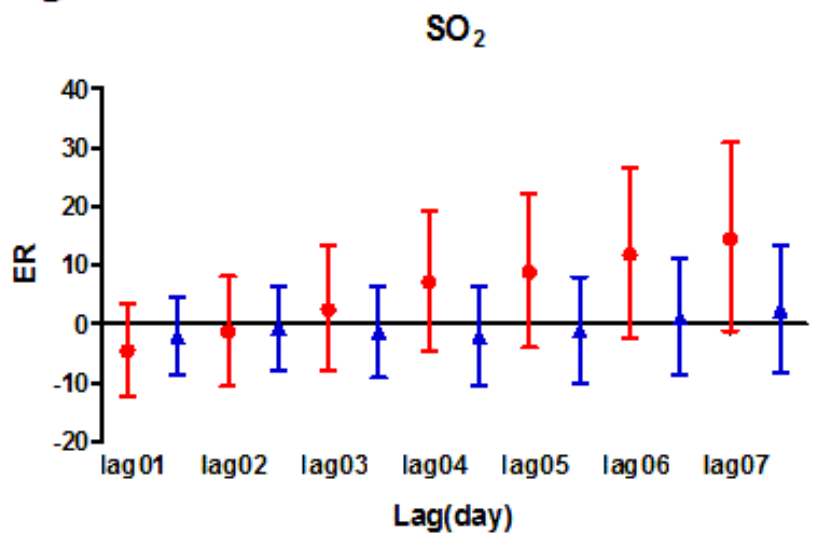

$\mathbf{E}$

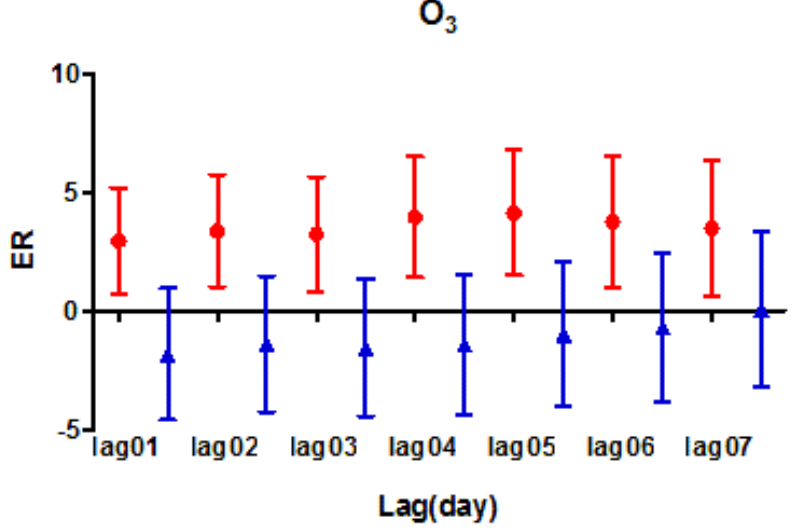

B $\mathrm{PM}_{10}$

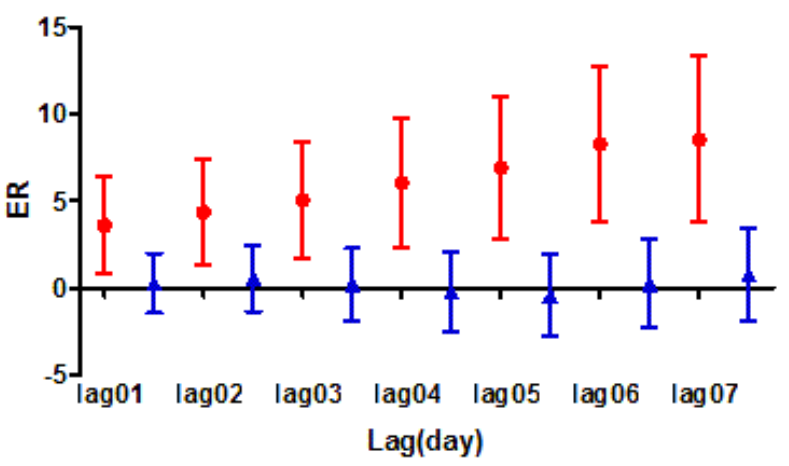

D

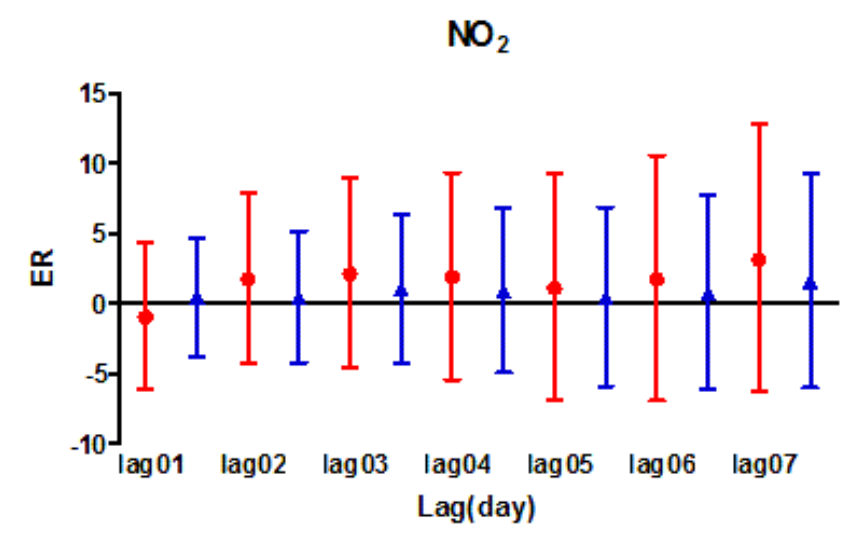

$\mathbf{F}$

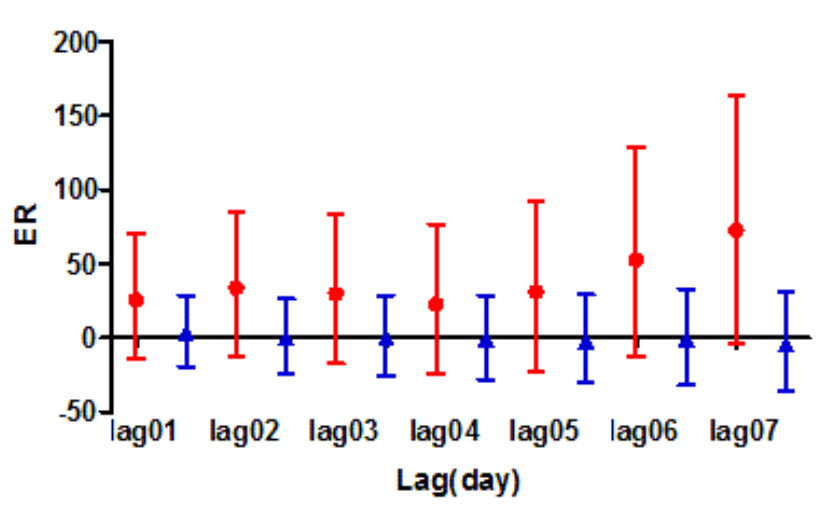

\section{Figure 4}

Comparison of excess risk(ER) in different seasons Notes: excess risk (ER) with 95\% Cls in multiday lag model for COPD admission visits with per $10 \mu \mathrm{g} / \mathrm{m} 3$ increase in PM2.5 (A), PM10 (B), SO2 (C), NO2 (D), $03(E)$, and CO (F) levels in the warm season (in red color) and cold season (in blue color). For CO, percentage change in the relative risks corresponded to per $1 \mathrm{mg} / \mathrm{m} 3$ increase of CO levels. ER: excess 
risk; Cl: confidence interval; PM2.5: fine particulate matter; PM10: inhalable particles; SO2: sulfur dioxide; NO2: nitrogen dioxide; 03: ozone; CO: carbon monoxide. 